\title{
Starburst Cells Nondirectionally Facilitate the Responses of Direction-Selective Retinal Ganglion Cells
}

\author{
Chuan-Chin Chiao and Richard H. Masland \\ Howard Hughes Medical Institute, Massachusetts General Hospital, Harvard Medical School, Boston, \\ Massachusetts 02114
}

The mechanism of direction selectivity in retinal ganglion cells remains controversial. An important issue is how the starburst amacrine cells, which are known to provide a major synaptic input to the direction-selective ganglion cells, participate in the directional discrimination. Here, we present evidence that the cholinergic outputs of the starburst cells affect the responses of the ganglion cells symmetrically; they provide a feedforward excitation that facilitates the response of the ganglion cells to

Several controversies surround the mechanism of direction selectivity in retinal ganglion cells. Much evidence indicates that the starburst cell is an attractive substrate for the detection of moving stimuli (Masland et al., 1984; Vaney, 1990; Borg-Graham and Grzywacz, 1992; Famiglietti, 1992). Starburst cells synapse directly on the direction-selective (DS) ganglion cells, and both of the neurotransmitters released by them, acetylcholine and GABA, affect the firing of the ganglion cells. However, experiments on the necessity of starburst cells have yielded conflicting results. In one study, in the rabbit, a laser was used to ablate patches of starburst cells on either the preferred or null side of the cell, with no effect on direction selectivity ( $\mathrm{He}$ and Masland, 1997). In contrast, immunotoxin-mediated ablation of all of the starburst cells in mouse retina eliminated direction selectivity and optokinetic eye movements (Yoshida et al., 2001). The experiments reported here address one facet of the possible role of the starburst cells: the possibility that they might contribute to direction selectivity by selective excitation of the ganglion cell from one side of the receptive field. We tested whether the starburst cells facilitate responses to all directions of movement or only a subset of directions. We used a two-spot paradigm to first establish motion facilitation in the preferred direction and motion inhibition in the null direction (Amthor et al., 1996). To test for the presence of feedforward facilitation in the null direction, we removed the inhibition that normally prevents responses in the null direction, using the GABA antagonist picrotoxin (PTX) (Caldwell et al., 1978; Kittila and Massey, 1997). To ascertain whether this type of facilitation was mediated by the starburst cells, we then applied $d$-tubocurarine (curare), known to be an effective antagonist at the acetylcholine (ACh) receptors of the DS cells (Ariel and Daw, 1982; Kittila and Massey, 1997).

Received July 31, 2002; revised Sept. 27, 2002; accepted Sept. 27, 2002.

R.H.M. is a Senior Investigator of Research to Prevent Blindness.

Correspondence should be addressed to Dr. Richard H. Masland, Massachusetts General Hospital, 50 Blossom Street, Wellman 429, Boston, MA 02114. E-mail: masland@helix.mgh.harvard.edu.

Copyright (C) 2002 Society for Neuroscience $0270-6474 / 02 / 2210509-05 \$ 15.00 / 0$ movement in both the preferred and null directions. This seems to place a constraint on models of the directional discrimination in which the starburst cells participate, namely, that their cholinergic synapses be nondirectional in their effects on the ganglion cells.

Key words: retina; amacrine; starburst; acetylcholine; GABA; neurotransmitters

A feedforward facilitation caused by stimuli moving in the preferred direction was demonstrated originally by Barlow and Levick (1965) and has been confirmed repeatedly in the rabbit retina (Grzywacz and Amthor, 1993; Amthor et al., 1996). It is known that the DS cells receive a powerful cholinergic input from overlapping starburst amacrine cells, many of which extend well beyond the classic receptive field of the DS cells (Masland and Ames, 1976; Yang and Masland, 1994). In the turtle retina, Smith et al. (1996) studied the effects of picrotoxin on both two-spot inhibition and facilitation. In the presence of picrotoxin, facilitation became inconsistent, sometimes occurring in the null direction as well as the preferred direction. The authors suggested that this eliminates many one-step models of the DS process, requiring instead a model in which several stages (neurons) are involved. The experiments to be reported here represent, in part, an extension of their result on null-direction facilitation to the rabbit. This seemed important because, among other reasons, the direction-selective neurons of the turtle retina have certain differences (notably their distribution of preferred directions) from those of the rabbit (Bowling, 1980).

In the presence of GABAergic blockers, DS cells respond to image motion in any direction through the receptive field. Under most conditions (but see Grzywacz et al., 1998), the subsequent addition of nicotinic blockers reduces these responses symmetrically, indicating that the cholinergic excitation elicited by nulldirection motion matched that elicited by preferred-direction motion. Furthermore, laser ablation of null-side starburst cells significantly reduced the responses produced by null-direction motion in the presence of GABAergic blockers (Vaney et al., 2001). It has therefore been presumed that cholinergic excitation from starburst amacrine cells underlies a null-direction facilitation (Amthor et al., 1996), but this has never been tested directly by examining the effects of cholinergic antagonists on the facilitation. Because some leading models of DS involve asymmetric starburst-DS interactions (Euler et al., 2002; Taylor and Vaney, 2002) (S. I. Fried, T. A. Münch, F. S. Werblin, unpublished observations), it seemed important to have a positive understand- 
ing of the symmetry, or lack of it, of feedforward facilitation. We asked three questions. (1) In the rabbit retina, is there feedforward facilitation in the preferred direction, the null direction, or both? (2) If so, is the facilitation cholinergic, i.e., mediated by synapses of the starburst amacrine cells? (3) With null-direction inhibition removed, is there a difference in magnitude between facilitation in the preferred and null directions? The answers to these questions do not support decisively any particular model of the involvement of the starburst cells in direction selectivity. They do set a condition that all such models should meet.

\section{MATERIALS AND METHODS}

The methods for isolating and maintaining rabbit retinas, recording from them, and studying receptive fields have all been described in previous articles (Yang and Masland, 1994; He and Masland, 1997). Briefly, New Zealand White rabbits of either sex, weighing 2-4 kg, were anesthetized by intramuscular injection of ketamine $(15-25 \mathrm{mg} / \mathrm{kg})$ and xylazine $(3-5$ $\mathrm{mg} / \mathrm{kg}$ ). The ganglion cells were labeled by injecting $1.5 \mu \mathrm{l}$ of 4,6diamidino-2-phenylindole (DAPI) $(1.5 \mu \mathrm{g})$ intraocularly. Topical anesthetic (proparacaine hydrochloride $0.5 \%$ ophthalmic solution) was applied to the surgical area, and the animal was allowed to recover. One to $3 \mathrm{~d}$ later, the animal was enucleated under deep anesthesia using ketamine $(30-100 \mathrm{mg} / \mathrm{kg}$ ) and xylazine $(5-10 \mathrm{mg} / \mathrm{kg})$. The animal was then killed with an intravenous overdose of ketamine according to a protocol approved by the Subcommittee on Research Animal Care of the Massachusetts General Hospital. The enucleated eye was hemisected and inverted over a Teflon post. The retina was carefully peeled off the pigment epithelium. A small piece of retina was cut off and attached to a cover glass, photoreceptor layer down, using tissue adhesive (Cell-Tak; Collaborative Research, Bedford, MA). This preparation was moved to a recording chamber attached to a microscope stage and superfused at $2.5-3.5 \mathrm{ml} / \mathrm{min}$ with oxygenated $\left(95 \% \mathrm{O}_{2}\right.$ and $\left.5 \% \mathrm{CO}_{2}\right)$ Ames' medium at $35-37^{\circ} \mathrm{C}$.

Stimuli were generated on a monochrome monitor (model 608; Tektronix, Wilsonville, OR) using a Picasso image synthesizer (Innisfree, Cambridgeshire, UK) driven by a 486 personal computer with userwritten software. Images were reflected upward by a mirror positioned beneath the microscope. A microscope objective $(20 \times$; numerical aperture, 0.4; Olympus Optical, Tokyo, Japan) replaced the condenser and focused the stimulus onto the photoreceptor layer of the retina. Luminance values on the stage were calibrated using a photodiode and photometer (LS-100; Minolta, Tokyo, Japan); they ranged from $<0.01$ to $12 \mathrm{~cd} / \mathrm{m}^{2}$, generally falling in the mesopic range.

Retinal ganglion cells labeled with DAPI were visualized under brief fluorescence illumination ( $365 \mathrm{~nm}$ excitation), and the ON-OFF DS cells were targeted with the aid of soma features described previously (Yang and Masland, 1994). The activity of single ganglion cells was recorded with tungsten-in-glass electrodes (Levick, 1972). A Schmidt trigger circuit identified action potentials; their time of occurrence relative to the stimulus generation was recorded by computer for later offline analysis. After an experiment, the recorded cell was usually injected with Lucifer yellow (4\%; Sigma, St. Louis, MO) and photographed (see Fig. 1A).

ON-OFF DS ganglion cells were identified initially by directionselective responses to a bar of light maneuvered manually. A flashing square $150 \times 150 \mu \mathrm{m}$ was then used to map the overall receptive field. The preferred-null axis was determined by using a bar $150 \times 300 \mu \mathrm{m}$ swept across the receptive field in eight different directions. Feedforward facilitation was studied by a two-spot protocol. To measure the strength of motion facilitation, the first spot, $200 \times 200 \mu \mathrm{m}$, was placed just outside of the excitatory center of the receptive field on either the preferred or the null side. By definition, the first spot caused no response. The second spot was displaced $230 \mu \mathrm{m}$ toward the center of the receptive field, so that the gap between spot 1 and spot 2 was $30 \mu \mathrm{m}$ (see Fig. 2, top). The stimulus duration was $1000 \mathrm{msec}$. The response of the cell to the second spot, either presented alone or preceded by the first, was measured.

Picrotoxin or $d$-tubocurarine (Sigma) was added to superfusate at 50 $\mu \mathrm{M}$ to selectively block the GABA inhibitory or ACh excitatory pathway, respectively. When PTX was used alone, the concentration of $\mathrm{Mg}^{2+}$ was raised from the normal $1.23-4.23 \mathrm{~mm}$. This suppressed the occasional spontaneous bursts of firing that occur in the presence of PTX. Under control conditions, the slightly elevated $\mathrm{Mg}^{2+}$ had no detectable effect on the spontaneous firing or the direction selectivity of the ganglion cells
(Masland and Ames, 1976). Tjepkes and Amthor (2000) specifically studied direction selectivity in the presence or absence of $\mathrm{Mg}^{2+}$; their results indicate that a small increase in $\mathrm{Mg}^{2+}$ would not be critical for direction selectivity. When PTX was used in combination with curare (see Fig. 2e,f), the spontaneous bursting was suppressed by loss of the cholinergic excitation, and the added $\mathrm{Mg}^{2+}$ was therefore not required. We omitted the extra $\mathrm{Mg}^{2+}$ because of a desire to use as few pharmacological manipulations as possible. Because it resulted in a rise in overall excitability, however, the reduction in $\mathrm{Mg}^{2+}$ did obscure the depression of response usually caused by curare (Ariel and Daw, 1982; He and Masland, 1997; Kittila and Massey, 1997).

\section{RESULTS}

Under control conditions, a slight facilitation of the response of the ganglion cells occurred during stimulation in the preferred sequence (Fig. 1B). This motion facilitation was seen as an increase of the response of the second spot when preceded by the first spot with a 100-500 msec delay. This result confirms a previous report (Amthor et al., 1996) of preferred direction facilitation. To ascertain whether this preferred direction facilitation was cholinergic, curare was added to superfusate at $50 \mu \mathrm{M}$ to selectively block cholinergic excitatory pathways. In the presence of curare, the preferred direction facilitation was entirely eliminated. The null-direction responses remained inhibitory in both control and $50 \mu \mathrm{M}$ curare conditions. This confirms the previous result that curare alone is not sufficient to eliminate direction selectivity (Ariel and Daw, 1982; He and Masland, 1997; Kittila and Massey, 1997).

Does feedforward facilitation occur when the stimulus moves in the null direction? If so, it would normally be masked by the large inhibition generated by null-direction stimuli. We therefore used $50 \mu \mathrm{M}$ PTX to selectively block the GABA inhibitory pathway and then applied $50 \mu \mathrm{M}$ PTX and $50 \mu \mathrm{M}$ curare together to examine facilitation in both directions. Under control conditions, a slight facilitation of the response of the ganglion cells occurred during stimulation in the preferred sequence (Fig. 2a). In the population of 27 cells tested, the interstimulus interval of 200$300 \mathrm{msec}$ gave the maximal facilitation of the second spot (Fig. 3, solid black line), which is close to the optimal speed $(1000 \mu \mathrm{m} / \mathrm{sec})$ to which the ON-OFF DS cell is tuned (Barlow et al., 1964). Note that facilitation under these conditions, although small, is the reverse of the effect observed for most types of ganglion cells, in which the first spot evokes surround inhibition. The striking event, of course, is the large depression of response observed when the paired spot sequence mimics movement in the null direction (Fig. 3). The effects described here were observed for both the $\mathrm{ON}$ and OFF components of the response; in the figures, they are combined.

In the presence of $50 \mu \mathrm{M}$ PTX (Fig. $2 c, d$ ), the null-direction inhibition was eliminated entirely (Caldwell et al., 1978; He and Masland, 1997; Kittila and Massey, 1997). Because it also removed the conventional surround inhibition, the excitatory center of the receptive field was enlarged under this condition (Caldwell et al., 1978). To maintain no response for the first spot alone, we moved the position of the first spot to a location just outside of the new excitatory center of the receptive field. Then, the position of the second spot was moved outward accordingly to maintain the same separation between the two spots as in the control conditions. Under these conditions, the paired spot facilitation was larger and more consistent than in the control conditions. More importantly, facilitation was observed for both the preferred and the null sequences. On average (Fig. 3), the interstimulus interval for the maximal facilitation under PTX (100-200 msec) was shorter than under control conditions (200-300 msec), possibly 

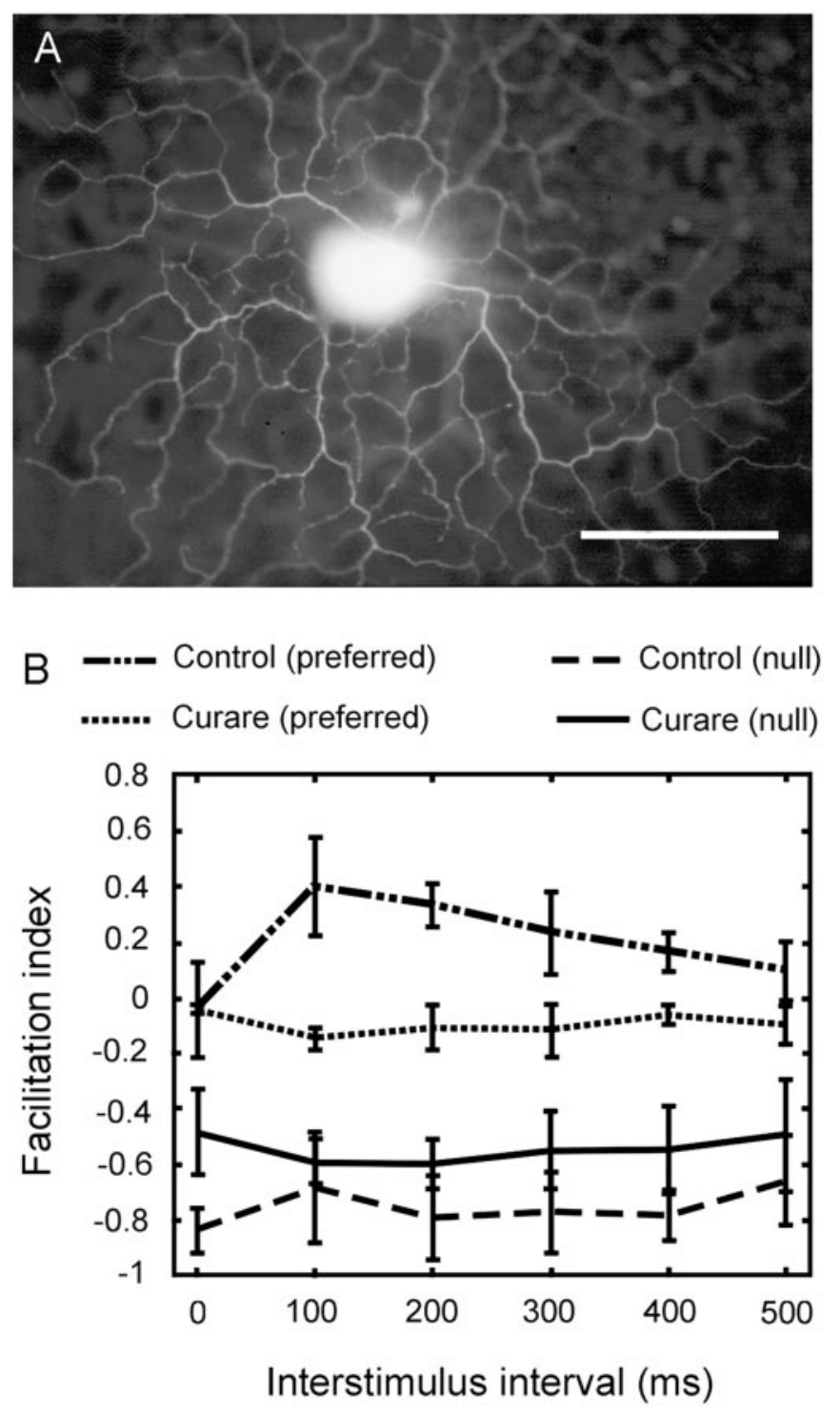

Figure 1. A, An ON-OFF DS cell injected with Lucifer yellow immediately after recording. The ON layer is in focus, with the OFF layer out of focus in the image. The characteristic morphology confirms the identity of the recorded unit as a classic ON-OFF DS cell. Scale bar, $100 \mu \mathrm{m} . B$, Two-spot apparent motion under control condition and in the presence of $50 \mu \mathrm{M}$ curare. The index of facilitation was calculated as $\left(R_{\mathrm{t}}-R_{0}\right) / R_{0}$, where $R_{\mathrm{t}}$ is response of the second spot when preceded by the first spot, and $R_{0}$ is the response of the second spot alone. The experimental paradigm is diagrammed in Figure 2. A negative facilitation index indicates inhibition. Data points show mean \pm SEM for three cells.

because facilitation was masked by the inhibition in the normal condition. Although all responses under PTX were more variable than in the control conditions, it was clear that the magnitude of facilitation in the absence of inhibition is increased drastically.

Starburst cells have a lateral dendritic extent that matches the spatial extent of the facilitation and are the only known excitatory amacrine cells (Famiglietti, 1983; Tauchi and Masland, 1984; Vaney, 1990); thus, they seemed likely to mediate the laterally directed facilitation. This was confirmed by the effect of curare, which eliminated almost entirely the previously large facilitation in both the preferred and the null directions (Fig. 2e,f, 3). In the presence of $50 \mu \mathrm{M}$ curare and $50 \mu \mathrm{M}$ PTX, the feedforward facilitation was replaced by a slight inhibition (possibly caused by
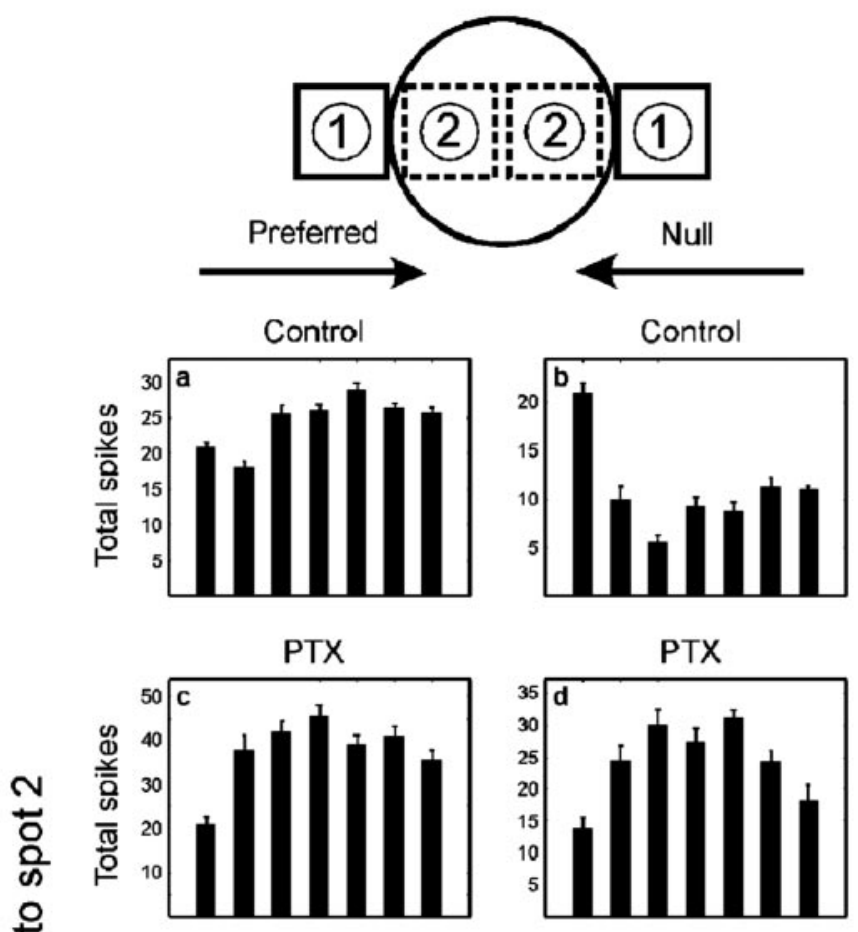

め)
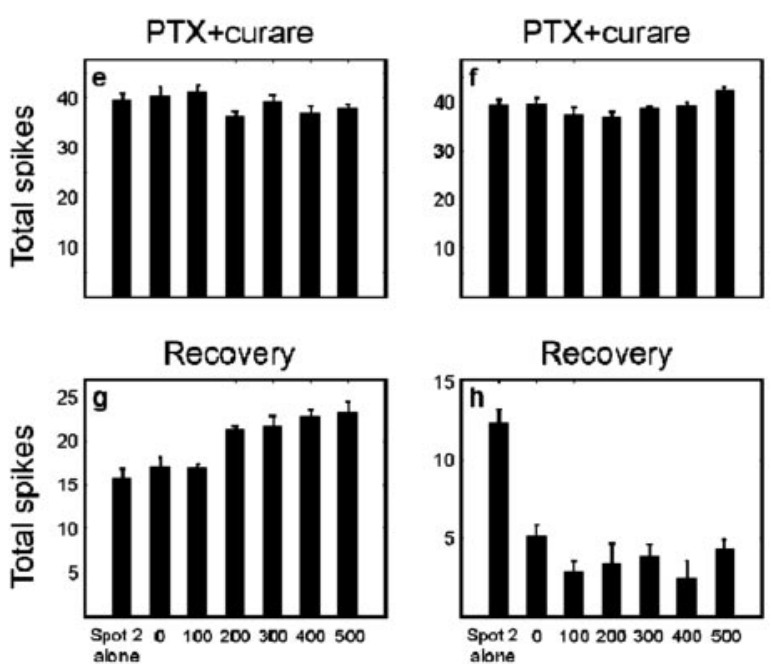

Interstimulus interval (ms)

Figure 2. Two-spot apparent motion experiment for an ON-OFF DS cell of the rabbit retina. The first spot was placed just outside of the excitatory center of receptive field for both preferred and null directions (the first spot alone caused no response). The second spot was placed 30 $\mu \mathrm{m}$ inward from the first spot. Responses to the second spot are shown, either alone or preceded by the first spot, with various delays $(0-500$ $\mathrm{msec}$ ). Ten trials were averaged for each stimulus sequence. Data shown are mean \pm SEM, and the ON and OFF components of the response are combined. Note that different ordinates are used under the various conditions (this was done to make the facilitation more easily compared). Pooled results for a population of cells are shown in Figure 3.

glycinergic amacrine cells). These results indicate that the cholinergic outputs of starburst amacrine cells isotropically facilitate responses of the ON-OFF DS cell. The size of the excitatory center of the receptive field under curare and PTX was close to that observed under control conditions. This implies that expansion of the excitatory center of the receptive field under PTX 

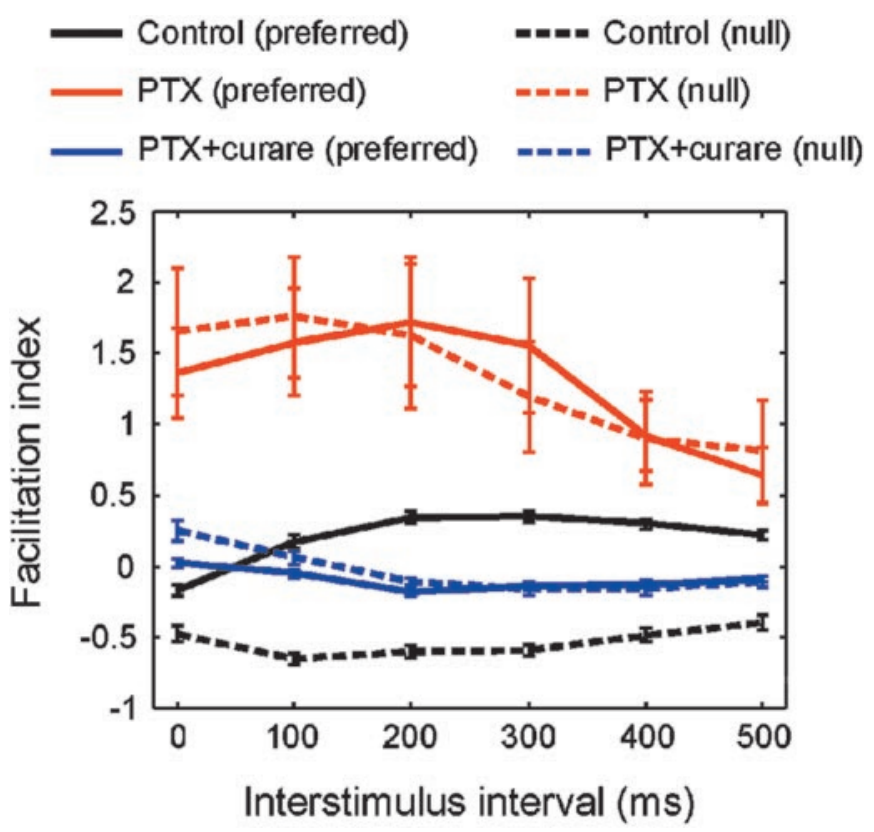

Figure 3. Pooled results $(n=27)$ for the two-spot apparent motion experiment described in Figure 2. The index of facilitation was calculated as in Figure 1. Data points show mean \pm SEM.

alone was a result of the unmasking of excitatory inputs from the starburst cells (Yang and Masland, 1994). When the retina was returned to control conditions, the responses recovered their original character (Fig. $2 g, h$ ).

\section{DISCUSSION}

Under our experimental conditions, the overall effects of the cholinergic outputs of the starburst cells are not direction selective; instead, they provide a feedforward excitation that facilitates the response of the ganglion cells to movement in both the preferred and null directions. This is consistent with experiments showing that, under most stimulus conditions, the DS cell retains its direction selectivity in the presence of cholinergic antagonists (Ariel and Daw, 1982; Grzywacz et al., 1997, 1998; He and Masland, 1997; Kittila and Massey, 1997).

How can this be reconciled with evidence (Yoshida et al., 2001) that immunolesion of the starburst cells abolishes direction selectivity? One possibility is that direction selectivity in the mouse and the rabbit are computed differently. There is no obvious morphological homolog in the mouse of the rabbit's ON-OFF DS cell (Sun et al., 2002). Direction selectivity has been reinvented many times in different species and different parts of the nervous system, and, it is possible, although an inelegant explanation, that there is a species difference.

An alternative is that the starburst cells perform both of the two computational stages (facilitation and inhibition), as suggested by Yoshida et al. (2001). In this case, the failure of laser ablation of a subset of starburst cells to eliminate direction selectivity (compared with total immunolesion in the mouse) would be attributed to the great redundancy of the starburst cell mosaic. Two events would contribute to the responses of the DS ganglion cell. First, a nonselective feedforward excitation facilitates the response of the cell to the moving stimulus. This may be conceptualized as a bidirectional Reichardt correlator (Fig. $4 a$ ). The starburst cells are remarkably well conserved across vertebrate retinas (Vaney, 1990), and it is tempting to speculate that

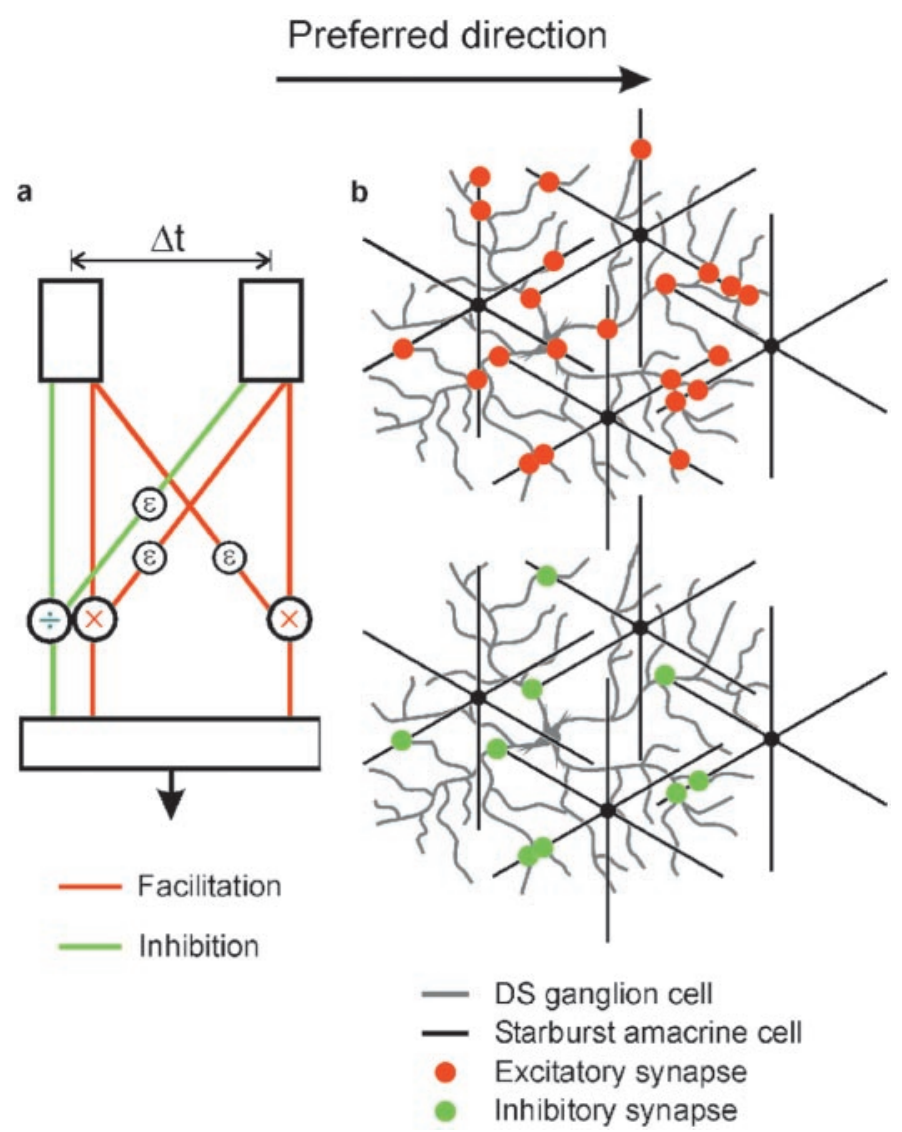

Figure 4. Schematic diagrams interpreting the present results. $a$, A two-stage model for the generation of direction selectivity. The first stage creates motion sensitivity by symmetric facilitation (red lines). The interaction is shown (conventionally) as multiplicative, but a nondirectional facilitation could be additive without fundamentally changing the overall concept. The second stage creates direction selectivity by asymmetric inhibition (green lines). Both stages require delay components $(\epsilon)$. The two stages could occur in sequence or in parallel and could in principle be mediated by the starburst cell plus another amacrine or by the starburst cell alone. $b$, If the starburst cells mediate both the facilitation and the inhibition, their excitatory synapses (red dots) would need to contact the DS cell nonselectively to account for symmetrical facilitation (present results), but their inhibitory, GABAergic synapses (green dots) would contact them asymmetrically (only on the left sides of the starburst cells). Excitatory and inhibitory synapses are shown in a restricted set of dendritic crossings because the outputs of the starburst cells are restricted to the distal third of their dendrites (Famiglietti, 1991). This diagram shows only four starburst cells, a small subset of the total that cover each DS cell (Tauchi and Masland, 1984); in actuality, red and green dots would cover the entire dendritic arbor of the DS cell uniformly (Jeon et al., 2002).

this nondirectional facilitory mechanism of ACh outputs represents an early, generic form of motion detection.

GABA-mediated inhibition would then depress the response of the cell to stimuli moving in the null direction. This inhibition could come from some as-yet-unidentified amacrine cell or from the starburst cells themselves, which are known to contain both acetylcholine and GABA (Brecha et al., 1988; Vaney and Young, 1988; O'Malley et al., 1992). The latter arrangement is shown in Figure $4 b$. If the starburst cells mediate both the facilitation and the inhibition, their excitatory synapses (red dots) would need to contact the DS cell nonselectively to account for symmetrical facilitation (present results), but their inhibitory, GABAergic synapses (green dots) would contact them asymmetrically (in the example, only on the left sides of the starburst cells). This model 
has the virtue of parsimony but poses the developmental challenge shown in Figure $4 b$, namely, that the cholinergic synapses of the starburst cells are symmetrical but their GABAergic synapses are directionally biased.

A different type of alternative is that several presynaptic cells participate jointly in the directional discrimination (Smith et al., 1996; Grzywacz et al., 1997, 1999; Kittila and Massey, 1997). A simple model of this type would be that an asymmetrical GABA input gates the release of an excitatory transmitter (Kittila and Massey, 1997). The excitatory transmitter could be acetylcholine from the starburst cells, glutamate from a bipolar cell, or both. Many variants on a multineuronal model are possible. Which is best depends substantially on whether the computation happens presynaptically or postsynaptically, at present a disputed experimental question (Taylor et al., 2000; Borg-Graham, 2001, Taylor and Vaney, 2002).

\section{REFERENCES}

Amthor FR, Grzywacz NM, Merwine DK (1996) Extra-receptive-field motion facilitation in on-off directionally selective ganglion cells of the rabbit retina. Vis Neurosci 13:303-309.

Ariel M, Daw NW (1982) Pharmacological analysis of directionally selective rabbit retinal ganglion cells. J Physiol (Lond) 324:161-185.

Barlow HB, Levick WR (1965) The mechanism of directionally selective units in rabbit's retina. J Physiol (Lond) 178:477-504.

Barlow HB, Hill RM, Levick W R (1964) Retinal ganglion cells responding selectively to direction and speed of image motion in the rabbit. J Physiol (Lond) 173:377-407.

Borg-Graham LJ (2001) The computation of directional selectivity in the retina occurs presynaptic to the ganglion cell. Nat Neurosci 4:176-183.

Borg-Graham LJ, Grzywacz NM (1992) A model of the directional selectivity circuit in retina: transformations by neurons singly and in concert. In: Single neuron computation (McKenna T, Davis J, Zornetzer SF, eds), pp 347-376. New York: Academic.

Bowling DB (1980) Light responses of ganglion cells in the retina of the turtle. J Physiol (Lond) 299:173-196.

Brecha N, Johnson D, Peichl L, Wässle H (1988) Cholinergic amacrine cells of the rabbit retina contain glutamate decarboxylase and gammaaminobutyrate immunoreactivity. Proc Natl Acad Sci USA 85:6187-6191.

Caldwell JH, Daw NW, Wyatt HJ (1978) Effects of picrotoxin and strychnine on rabbit retinal ganglion cells: lateral interactions for cells with more complex receptive fields. J Physiol (Lond) 276:277-298.

Euler T, Detwiler PB, Denk W (2002) Directionally selective calcium signals in dendrites of starburst amacrine cells. Nature 418:845-852.

Famiglietti EV (1983) "Starburst" amacrine cells and cholinergic neurons: mirror-symmetric $\mathrm{ON}$ and $\mathrm{OFF}$ amacrine cells of rabbit retina. Brain Res 261:138-144.

Famiglietti EV (1991) Synaptic organization of starburst amacrine cells in rabbit retina: analysis of serial thin sections by electron microscopy and graphic reconstruction. J Comp Neurol 309:40-70.

Famiglietti EV (1992) Dendritic co-stratification of ON and ON-OFF directionally selective ganglion cells with starburst amacrine cells in rabbit retina. J Comp Neurol 324:322-335.

Grzywacz NM, Amthor FR (1993) Facilitation in ON-OFF directionally selective ganglion cells of the rabbit retina. J Neurophysiol 69:2188-2199.

Grzywacz NM, Tootle JS, Amthor FR (1997) Is the input to a GABAergic or cholinergic synapse the sole asymmetry in rabbit's retinal directional selectivity? Vis Neurosci 14:39-54.

Grzywacz NM, Amthor FR, Merwine DK (1998) Necessity of acetylcholine for retinal directionally selective responses to drifting gratings in rabbit. J Physiol (Lond) 512:575-581.

Grzywacz NM, Merwine DK, Amthor FR (1999) Complementary roles of two excitatory pathways in retinal directional selectivity. Vis Neurosci 15:1119-1127.

He S-G, Masland RH (1997) Retinal direction selectivity after targeted laser ablation of starburst amacrine cells. Nature 389:378-382.

Jeon C-J, Kong J-H, Strettoi E, Rockhill RL, Stasheff SF, Masland RH (2002) Pattern of synaptic excitation and inhibition upon directionselective retinal ganglion cells. J Comp Neurol 449:195-205.

Kittila CA, Massey SC (1997) The pharmacology of directionally selective ganglion cells in the rabbit retina. J Neurophysiol 77:675-689.

Levick WR (1972) Another tungsten microelectrode. Med Biol Eng 10:510-515.

Masland RH, Ames A (1976) Responses to acetylcholine of ganglion cells in an isolated mammalian retina. J Neurophysiol 39:1220-1235.

Masland RH, Mills JW, Cassidy C (1984) The functions of acetylcholine in the rabbit retina. Proc R Soc Lond B Biol Sci 223:121-139.

O'Malley DM, Sandell JH, Masland RH (1992) Co-release of acetylcholine and GABA by the starburst amacrine cells. J Neurosci 12:1394-1408.

Smith RD, Grzywacz NM, Borg-Graham LJ (1996) Is the input to a GABAergic synapse the sole asymmetry in turtle's retinal directional selectivity? Vis Neurosci 13:423-439.

Sun W, Li N, He S (2002) Large-scale morphological survey of mouse retinal ganglion cells. J Comp Neurol 451:115-126.

Tauchi M, Masland RH (1984) The shape and arrangement of the cholinergic neurons in the rabbit retina. Proc R Soc Lond B Biol Sci 223:101-119.

Taylor WR, Vaney DI (2002) Diverse synaptic mechanisms generate direction selectivity in the rabbit retina. J Neurosci 22:7712-7720.

Taylor WR, He S, Levick WR, Vaney DI (2000) Dendritic computation of direction selectivity by retinal ganglion cells. Science 289:2347-2350.

Tjepkes DS, Amthor FR (2000) The role of NMDA channels in rabbit retinal directional selectivity. Vis Neurosci 17:291-302.

Vaney DI (1990) The mosaic of amacrine cells in the mammalian retina. In: Progress in retinal research (Osborne N, Chader G, eds), pp 49-100. New York: Pergamon.

Vaney DI, Young HM (1988) GABA-like immunoreactivity in cholinergic amacrine cells of the rabbit retina. Brain Res 438:369-373.

Vaney DI, He S, Taylor WR, Levick WR (2001) Direction-selective ganglion cells in the retina. In: Motion vision: computational, neural, and ecological constraints (Zanker J, Zeil J, eds), pp 13-55. Berlin: Springer.

Yang G, Masland RH (1994) Receptive fields and dendritic structure of directionally selective retinal ganglion cells. J Neurosci 14:5267-5280.

Yoshida K, Watanabe D, Ishikane H, Tachibana M, Pastan I, Nakanishi S (2001) A key role of starburst amacrine cells in originating retinal directional selectivity and optokinetic eye movement. Neuron 30:771780 . 